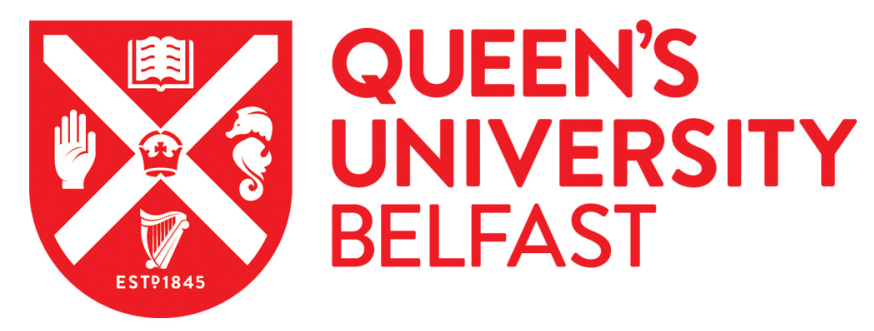

\title{
Self-efficacy, habit strength, health locus of control and response to the personalised nutrition Food4Me intervention study
}

J Stewart-Knox, B., Rankin, A., P Bunting, B., J Frewer, L., Celis-Morales, C., M Livingstone, K., Fischer, A. R. H., Poínhos, R., Kuznesof, S., J Gibney, M., \& Mathers, J. C. (2022). Self-efficacy, habit strength, health locus of control and response to the personalised nutrition Food4Me intervention study. British Food Journal, 124(1), 314-330. https://doi.org/10.1108/BFJ-03-2021-0221

Published in:

British Food Journal

Document Version:

Peer reviewed version

Queen's University Belfast - Research Portal:

Link to publication record in Queen's University Belfast Research Portal

Publisher rights

Copyright 2021, Emerald Publishing Limited.

This work is made available online in accordance with the publisher's policies. Please refer to any applicable terms of use of the publisher.

\section{General rights}

Copyright for the publications made accessible via the Queen's University Belfast Research Portal is retained by the author(s) and / or other copyright owners and it is a condition of accessing these publications that users recognise and abide by the legal requirements associated with these rights.

Take down policy

The Research Portal is Queen's institutional repository that provides access to Queen's research output. Every effort has been made to ensure that content in the Research Portal does not infringe any person's rights, or applicable UK laws. If you discover content in the Research Portal that you believe breaches copyright or violates any law, please contact openaccess@qub.ac.uk. 
1 Self-efficacy, habit strength, health locus of control and response to the personalised

\section{nutrition Food4Me intervention study}

Barbara Stewart-Knox $\mathrm{PhD}^{\mathrm{a}}$, Audrey Rankin $\mathrm{PhD}^{\mathrm{b}}$, Brendan Bunting $\mathrm{PhD}^{\mathrm{c}}$, Lynn Frewer $\mathrm{PhD}^{\mathrm{d}}$ Carlos Celis-Morales $\mathrm{PhD}^{\mathrm{e}}$, Katherine Livingstone $\mathrm{PhD}^{\mathrm{f}}$, Arnout Fischer $\mathrm{PhD}^{\mathrm{g}}$, Rui Poínhos $\mathrm{PhD}^{\mathrm{h}}$, Sharron Kuznesof $\mathrm{PhD}^{\mathrm{d}}$, Mike Gibney $\mathrm{PhD}^{\mathrm{i}}$ John C. Mathers $\mathrm{PhD}^{\mathrm{d}}$

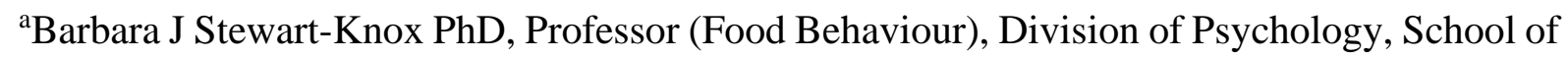
Social Sciences, University of Bradford, Richmond Road, Bradford BD71DP, UK. Tel: +44(0)1274233514. B.stewart-knox@ @bradford.ac.uk. ORCID ID: 0000-0002-6741-3657.

${ }^{\mathrm{b}}$ Audrey Rankin PhD, Research Fellow, School of Pharmacy, Queen's University Belfast 97 Lisburn Road, Belfast BT9 7BL. Tele: +44 (0) 289097 2348. a.rankin@qub.ac.uk ORCID ID: 0000-0002-3241-0536.

${ }^{\mathrm{c} B r e n d a n}$ P. Bunting PhD Professor, School of Psychology, Ulster University, Cromore Road, Coleraine, County Londonderry, BT52 1SA. Tel: 028 90775048. bp.bunting@ulster.ac.uk. ORCID ID: 0000-0002-7219-6773.

${ }^{\mathrm{d}}$ Lynn Frewer PhD, Professor (Food and Society) School of Natural and Environmental Sciences, Newcastle University, Newcastle Upon Tyne NE191AA, UK. Tel: 01912088272 lynn.frewer@newcastle.ac.uk. ORCID ID: 0000-0002-6494-3492.

${ }^{\mathrm{e} C}$ Carlos Celis-Morales $\mathrm{PhD}$, Research Fellow, Institute of Cardiovascular and Medical Science, University of Glasgow, Glasgow, UK. G12 8TA. Tel: +44(0)1413304201. Carlos.celis@glasgow.ac.uk ORCID ID: 0000-0003-2612-3917.

${ }^{\mathrm{f}}$ Katherine M Livingstone PhD, NHMRC Emerging Leadership Fellow, Deakin University, Institute for Physical Activity and Nutrition Research (IPAN), School of Exercise and Nutrition Sciences, Melbourne Burwood Campus, 221 Burwood Highway, Burwood VIC 3125 Australia. Tel: +61 39244 5416. k.livingstone@ deakin.edu.au. ORCID ID: 0000-0002-96827541. 
${ }^{\text {g}}$ Arnout R.H. Fischer PhD, Associate Professor (consumer behaviour), Wageningen University, Social-Sciences, Marketing and Consumer Behaviour, Hollandseweg 1; 6706

KN Wageningen, The Netherlands. Tel: + 313174830 53. Arnout.Fischer@wur.nl. ORCID ID: 0000-0003-0474-5336.

${ }^{\text {h}}$ Rui Poínhos PhD, Invited Assistant Professor, Faculty of Nutrition and Food Sciences, University of Porto, Rua do Campo Alegre, n. ${ }^{8} 823$ - 4150-180 Porto, Portugal. Tel: +351 225074320. ruipoinhos@ fcna.up.pt ORCID ID: 0000-0002-9177-6423.

Sharron Kuznesof PhD, Senior Lecturer, School of Natural and Environmental Sciences, Newcastle University, Newcastle upon Tyne, NE17RU, UK. Tel: 00441912086900. ${ }^{\mathrm{d} S h a r r o n . k u z n e s o f @ n c l . a c . u k}$. ORCID ID: 0000-0001-8630-423X.

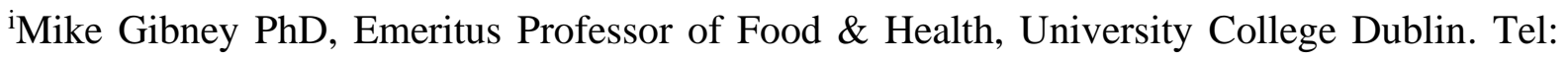
+353 872415 156. Mike.Gibney@ucd.ie ORCID ID: 0000-0001-5250-361X.

${ }^{\mathrm{d} J o h n}$ C. Mathers PhD, Professor, Director Human Nutrition Research Centre, Newcastle University, Newcastle upon Tyne, NE24HH, UK. Tel: $\quad+44(0) 1912081133$ john.mathers@ncl.ac.uk. ORCID ID: 0000-0003-3406-3002.

Corresponding author: Barbara Stewart-Knox. Division of Psychology, University of Bradford, Richmond Road, Bradford BD7 1DP. Tel: 0044(0)1274233514 Email: b.stewartknox@bradford.ac.uk

\section{ACKNOWLEDGEMENTS}

Food4Me is the acronym of the EU FP7 Project "Personalised nutrition: an integrated analysis of opportunities and challenges" (Contract No. KBBE.2010.2.3-02, Project No.265494) http://www.food4me.org/. 


\section{AUTHOR CONTRIBUTIONS}

52 The intervention study was designed by JM, and MG. Psychological constructs for analysis 53 were selected by LF, BS-K, AR, RP and AF. CC-M and KL were involved in data collection 54 and analysis. The plan for analysis was devised by BS-K, BB, RP, IL and JM. BS-K drafted the manuscript. LF, JM, CC-M, RP, AR, SK and AF commented on the draft manuscript.

\section{CONFLICT OF INTEREST STATEMENT}

58

59

60

61

62

63

64

65

66

67

68

69

70

71

72 
Self-efficacy, habit strength, health locus of control and response to the personalised nutrition Food4Me intervention study

\section{ABSTRACT}

Purpose: Randomised controlled trials identify causal links between variables but not why an outcome has occurred. This analysis sought to determine psychological factors assessed at baseline influenced response to personalised nutrition. Design: Web-based, randomised, controlled trial (RCT) was conducted across seven European countries. Volunteers, both male and female, aged over 18 years were randomised to either a non-personalised (control) or a personalised (treatment) dietary advice condition. Linear Mixed Model Analysis with fixed effects was used to compare associations between Internal and External Health Locus of Control (HLoC), Nutrition Self-Efficacy (NS-E) and Self-Report Habit Index (S-RHI) at baseline (N=1444), with Healthy Eating Index (HEI) and Mediterranean Diet Index (MDI) scores between conditions post-intervention (N=763). Findings: An increase in MDI scores was observed between baseline and six months in the treatment group which was associated with higher NS-E $(P<0.001)$, S-RHI $(P<0.001)$ and external HLoC $(P<0.001)$. Increase in HEI between baseline and six months in the treatment group was associated with higher NS-E $(P<0.001)$ and external HLoC $(P=0.009)$. Interaction between time and condition indicated increased HEI scores $(P<0.001)$ which were associated with higher S-RHI scores in the treatment than control group $(P=0.032)$. Internal HLoC had no effect on MDI or HEI. Originality: Psychological factors associated with behaviour change need consideration when tailoring dietary advice. Those with weaker habit strength will require communication focussed upon establishing dietary habits and support in integrating advised changes into daily routine. Information on habit strength can also be used to inform how progress toward dietary goals are monitored and fed back to the individual. Those with stronger habit strength are more likely to benefit from personalised nutrition. 
98 Key words: self-efficacy; health locus of control; habit strength; Healthy Eating Index;

99 Mediterranean diet. 
Personalised nutrition uses information about an individual to deliver tailored dietary advice (Ordovas et al., 2018) and could offer an effective way of motivating people to improve their diet-related behaviour and so to improve their health (Celis-Morales et al., 2014). Randomised controlled trials (RCT), represent the gold-standard for inferring causality i.e. whether a particular condition or variable had an effect on an outcome when all other variables are held constant (Celis-Morales et al., 2014). Previous studies have indicated that personalised advice is more effective than generic advice in producing healthy dietary change (Rollo et al., 2020; Hoevaars et al., 2020; Celis-Morales et al., 2015). Even when the outcome of a dietary intervention is known, however, it is important to understand the psychological processes that may be involved in achieving the outcome so that future benefits can be maximised (Olsen, 2016). A key issue is inter-individual variability in response to interventions (Madden et al., 2011). Understanding the psychology underlying inter-individual variability in response could prove valuable when designing future interventions. Individuals may respond differently to intervention depending upon their psychological propensity for behaviour change (Galekop et al., 2021; Greiner et al., 2018; Anderson et al., 2000).

A review of digitally delivered healthy eating interventions (Olsen, 2016) concluded that approximately $75 \%$ of studies that provided feedback based upon behavioural theories resulted in short-term healthy change. A recent RCT (Rollo et al., 2020), for example, has indicated that aspects of Social Cognitive Theory (SCT) such as self-monitoring and feedback may be particularly important to motivation. Qualitative research (Rankin et al., 2016; StewartKnox et al., 2013) and survey of European consumers (Poínhos et al., 2014), suggested that constructs associated with SCT such as nutrition self-efficacy (NS-E), health locus of control (HLoC) and habit strength (S-RHI) were potentially important factors determining intention to adopt personalised nutrition. While there has been much emphasis on behaviour change 
techniques, less attention has been paid to the impact of psychological variables upon intervention. These constructs were therefore included in the questionnaire administered to participants in this intervention trial rendering it one of few studies to have quantified markers 2018).

Habit refers to the non-cognitive (automatic), learned, component of behaviour (Gardner et al., 2011). Past dietary habits are important to future intentions and food choices (Verhoeven et al., 2012; de Bruijn, 2010). Habit strength assessed using the self-report habit index (S-RHI) (Honkanen et al., 2005; Verplanken and Orbell, 2003) has been associated with intake of high energy snacks (Wouters et al., 2018; Naughton et al., 2015), and with intention 
Cheng et al., 2016; Ryon and Gleeson, 2014). HLoC is considered an important mediator of health behaviour change (Davey et al., 2019; Jang and Baek, 2018; Marteau et al., 2010). HLoC can be internal, reflecting the extent to which outcomes are perceived to be determined by the individual themselves, or external, the degree to which control is perceived to be determined by chance and/or other individuals (Ryon and Gleeson, 2014). where non-clinical, general populations have been studied, higher internal HLoC has been associated with healthier eating (Davey et al., 2019; Rongen et al., 2014; Cobb-Clark et al., 2014; Murphy et al., 2001; Paxton and Scunthorpe, 1999; Callaghan, 1998). Conversely, those who have a low internal HLoC consider their health to be less under their own control may be less likely to follow dietary advice (Marteau et al., 2014; Frosch et al., 2005). Previous research that has considered external HLoC has been mixed and while one study identified a link to healthier eating (Jang and Baek, 2018), other studies have found it to be associated with less healthy dietary habits (Gomez et al., 2018; Cheng et al., 2016).

Self-efficacy refers to perceived ability to complete a specific task (Bandura, 1997), implying that behaviour change is most likely when self-efficacy is high (Witte and Allen, 2000). Consistent with this theory, cross-sectional studies in clinical populations (Greiner et al., 2018; Gomez et al., 2018; Hwang, 2016; Ferranti et al., 2014) and apparently healthy populations (Lo et al., 2019; Churchill et al., 2019; Kushida et al., 2017; Swan et al., 2015; Williams et al., 2012; Brug et al., 2006; Anderson et al., 2000) have linked higher self-efficacy to healthier food choices. Greater self-efficacy has been linked to more frequent fruit and vegetable intake (Smith et al., 2020; Lo et al., 2019; Welch and Ellis, 2018; Kushida et al., 2017; Brug et al., 2006), reduced fast food intake (Smith et al., 2020) and less snacking (Churchill et al., 2019). Conversely, lower self-efficacy has been associated less healthy food choices (Williams et al., 2012; de Bruijn and van der Putte, 2009) and low perceived ability to cook healthy food (de Borba et al., 2021). Evidence from recent RCT (Bouwman et al., 2020) 
has indicated that higher self-efficacy can improve vegetable intake and adherence to healthy eating plans. Recent research (Bracken and Waite, 2020) and systematic review (Newby et al., 2020) have implied that self-efficacy is associated with response to digitally-delivered behaviour change interventions. Together, this suggests that individuals with higher NS-E would be more likely to achieve healthy dietary behaviour changes following personalised nutrition advice.

Primary results from the Food4Me personalised nutrition intervention observed greater improvements in dietary quality in response to personalised nutrition than non-personalised dietary advice (Celis-Morales et al., 2017; Livingstone et al., 2016a; Livingstone et al., 2016a; Celis-Morales et al., 2015). This analysis aims to determine the moderating effect that psychological factors associated with behaviour change have on response to personalised nutrition. Knowledge of these effects will allow the design of future interventions that are strengthened by the specific psychological construct levels individuals may have. By understanding what psychological factors contribute to an individual's response to personalised nutrition, we can then tailor advice that is optimally supported by understanding of their internal health locus of control, self-efficacy and/or habit strength. A secondary data analysis, therefore, has been conducted to investigate if baseline psychological traits contribute to the differences in response to personalised nutrition.

The purpose of this analysis, therefore, has been to determine the impact of Health Locus of Control (HLoC) (Internal and External), Nutrition Self-Efficacy (NS-E) and Habit Strength (S-RHI), at baseline upon dietary response to personalised versus non-personalised dietary advice. This was achieved by investigating associations between baseline psychological factors and HEI and MDI scores in response to non-personalised dietary advice (Level 0: Control) and differences in personalised nutrition advice (Levels 1 to 3 versus Treatment). Social cognitive theory (SCT) holds that self-efficacy and perceived control are interlinked 

According to SCT, individuals with low self-efficacy and high External HLoC will be less likely to alter dietary habits in response to dietary interventions (Joost et al., 2007). It is predicted, therefore, that those higher in NS-E with higher Internal HLoC, lower External HLoC and higher habit strength (S-RHI) will be more likely to respond positively to personalised nutrition advice and that this will be reflected in higher HEI and MDI scores.

\section{METHOD}

Analysis was conducted on anonymised data collected as part of a web-based RCT (NCT01530139) conducted between August 2012 and December 2014 and which compared dietary response to personalised nutrition and Control (non-personalised) healthy eating advice. This study was conducted according to the guidelines laid down in the declaration of Helsinki and all procedures were approved by the Ethics committee of each recruiting centre: University College Dublin, Ireland; Maastricht University, Netherlands; University of Navarra, Spain; Harokopio University, Greece; University of Reading, UK; National Food and Nutrition Institute, Poland; and, Technische Universität München, Germany. All participants were informed of the study purpose and procedures prior to providing written consent.

\section{Sampling}

Details of recruitment, data collection procedures and intervention protocol have been reported previously. ${ }^{51}$ Volunteers, both male and female, aged $18+$ years were recruited to the 6 -month online nutrition intervention study. Exclusion criteria were: pregnant or lactating; following a prescribed diet; having a metabolic condition which could alter their nutritional requirements; and, having no or limited internet access. Eligible volunteers $(\mathrm{N}=1607)$ were stratified by 
country (UK, Greece, Spain, Poland, Ireland, Germany and the Netherlands), sex and age before being equally allocated to one of three Treatment conditions using an urn randomisation scheme (Wei and Lachin 1988). Treatments were personalised advice based on: i) current diet assessed on healthy eating guidelines and anthropometry $(n=414)$; ii) current diet and anthropometry plus phenotype (blood glucose, total serum cholesterol, carotenes and n-3 index) (n=404); iii) current diet and anthropometry plus phenotype plus genotype (specific variants of the following genes: MTHFR, FTO, TCF7L2, APOE $\varepsilon 4$ and FADS1) (n=402). The Control group $(n=387)$ received non-personalised healthy eating advice based on European recommendations to reduce fat and salt intake and encouraging consumption of fish, fruit and vegetables (Control). The trial was single-blinded so that researchers did not know to which treatment participants were allocated. Psychological outcomes were available for 1507 cases at baseline, of whom 387 were in the control group and 1120 who underwent the personalised nutrition treatment. Of these, as a result of attrition, dietary outcomes were recorded for 763 post-intervention.

\section{Measures}

A questionnaire, the content of which was informed by prior qualitative research (StewartKnox et al., 2013; Rankin et al., 2016), was issued at baseline via an email link to assess health locus of control, nutrition self-efficacy and habit strength.

Health Locus of Control

Health locus of control (Gebhardt et al., 2001) was measured by six items taken from the Revised Health Hardiness Inventory (RHHI-24) for which responses were on a 5-point Likert scale ranging from $1=$ 'Completely disagree' to $5=$ 'Completely agree'. The RHHI-24 comprises 4 scales: health as a value; perceived health confidence; IHLoC; and, EHLoC. Given the need to constrain the length of the questionnaire and the focus upon HLoC, the first three 
items of the IHLoC and EHLoC scales were extracted for inclusion. Items selected to measure

IHLoC were: "I can be as healthy as I want to be"; "I am in control of my health"; "I can pretty much stay healthy by taking care of myself"; and "Efforts to improve your health are a waste

252 of time" (which was reverse scored). Items used to measure HLoC were: "I am bored by all the attention that is paid to health and disease prevention"; "What's the use of concerning yourself about your health you'll only worry yourself to death". As these items were negatively worded the 5-point Likert scales were reverse scored. Reliability was satisfactory with Cronbach's $\alpha=$ 0.73 for IHLoC and $\alpha=0.60$ for EHLoC.

\section{Nutrition Self-Efficacy}

Nutrition self-efficacy (NS-E) was measured using Schwarzer and Renner's (2000) Perceived Self-Efficacy Scale (PS-ES). The scale was adapted from a 4-point to a 5-point scale to align responses with others in the questionnaire. Respondents were asked how certain they were they could 'manage to stick to healthy foods, even if' on a scale ranging from $1=$ 'Very uncertain' to $5=$ 'Very certain', in response to the following items: "I need a long time to develop the necessary routines"; "I have to try several times until it works"; "I have to rethink my entire way of nutrition"; "I do not receive a great deal of support from others when making my first attempts"; "I have to make a detailed plan". Reliability was good with Cronbach's $\alpha=$ 0.87 .

\section{Habit Strength}

Habit Strength was assessed using four items measuring each facet of habit (frequency; lack of awareness; lack of control; and, mental efficiency) previously employed by Honkanen and colleagues (2005) and adapted from Verplanken \& Orbell's (2003) Self-Report Habit Index (S-RHI). Responses were on a 5-point Likert scale ranging from $1={ }^{\text {C Completely }}$ disagree' to $5=$ 'Completely agree', to the following statements: "Eating healthily is something I do frequently"; "I eat healthily without having to consciously think about it"; "I feel weird if 
I don't eat healthily"; "Eating healthily is something I do without having to think about it".

Each item was scored and summed on four dimensions: frequency of behaviour; awareness; lack of control; and, mental efficiency. Reliability was satisfactory Cronbach's $\alpha=0.73$. Food Frequency Questionnaire Procedures for computing Healthy Eating Index (HEI) and Mediterranean Diet Index (MDI) scores have been reported previously by Livingstone and colleagues (2016 a and b). Briefly, a validated 157-item food frequency questionnaire (FFQ) developed and validated for the study (Marshall et al., 2016; Fallaize et al., 2014; Forster et al., 2014) was completed online at baseline and at six months. Responses were graded on 14 criteria to determine adherence to the Mediterranean diet (Livingsone et al., 2016a; Martinez-Gonzalez et al., 2012). Diet quality was also assessed using the healthy eating index (HEI) updated (2010) version (Guenther et al., 2014). The HEI-2010 includes 12 food groups, 9 of which assess adequacy of the diet, including 1) total fruit; 2) whole fruit; 3) total vegetables; 4) greens and beans; 5) whole grains; 6) dairy; 7) total protein foods; 8) seafood and plant proteins; and 9) fatty acids. The remaining 3, refined grains, sodium, and empty calories (i.e., energy from solid fats, alcohol, and added sugars), assess dietary components that should be consumed in moderation. For all components, higher scores reflect better diet quality because the less beneficial food groups are scored such that lower intakes receive higher scores. The scores of the 12 components were summed to yield a total score with a maximum value of 100 . The food groups of the HEI-2010 and their respective standards have been described in additional detail previously (Guenther et al., 2014). For all components, higher scores reflect better diet quality because the less beneficial food groups are scored such that lower intakes receive higher scores. The HEI (2010) and MDI both show good validity (Guenther et al., 2014) and changed in a positive direction in response to personalised nutrition advice (Celis-Morales et al., 2017; San- 


\section{Data Analysis}

301

Linear Mixed Model with fixed effects, with the assumption of compound symmetry relating to the variances and covariance, was used to examine effect of psychological traits assessed at baseline on HEI and MDI scores between the Control and Treatment groups and time point (baseline and post-intervention) (Field, 2018). Dietary and psychological data for the three Levels of personalised nutrition were combined to make one treatment group. Separate models were run for the HEI and MDI, with the treatment and control conditions together within each model. Associations between psychological factors and dietary outcomes (HEI/MDI) are reported for a given intervention level (ie. simple effect) as a way of analysing conditional/interaction data when there is a mixed regression analysis. Baseline NS-E; IHLoC; EHLoC; and, S-RHI scores were entered into the analysis as independent variables. Outcome variables were HEI and MDI scores calculated for the Treatment (personalised nutrition) and Control (non-personalised advice) groups. Model results are presented as unstandardized estimates (est) and standard errors (s.e.). Where data were available for a given occasion this was retained, and where missing, the estimation method employed (maximum likelihood), estimated the parameter under the assumption that missing data were missing at random. All analyses were conducted using SPSS for Windows version 25.0. $P$-values $<0.05$ were considered significant.

\section{RESULTS}

The eventual sample comprised those successfully followed-up at 6 months $(\mathrm{N}=763)$ and was predominantly $(96.9 \%)$ white European, of whom $42 \%$ were male, with a mean age of 40 years $(\mathrm{SD}=13)$ and a mean BMI of $25.4 \mathrm{~kg} / \mathrm{m}^{2}(\mathrm{SD}=4.8)$. Psychological traits appeared stable across the intervention period (Table 1). Those who completed the intervention were 
significantly higher in S-RHI than those who did not complete (Table 2). There were no differences between completers and non-completers in NS-E, IHLoC or EHLoC.

\section{Insert table 1 and 2 here}

\section{Healthy Eating Index (HEI)}

Main effects indicated that HEI scores increased between baseline and 6 months in the Treatment group (est=-2.54, se=0.39, $P<0.001)$ and were positively associated with higher EHLoC, S-RHI and NS-E (Table 3). There was no significant association between IHLoC and HEI in either the Treatment or Control group and no significant association between EHLoC or NS-E and HEI in the Control group. The level-1 variance was 41.22 (se = 2.15) and the level-2 variance for the random intercept was 42.51 ( $\mathrm{se}=3.07$ ).

\section{Insert Table 3 here}

\section{Time and Condition}

Taking the treatment condition from the second time-point (6 months) as the reference category, an interaction on time and condition was used. This can also be viewed as the comparison between those in the intervention conditions on the first occasion and its difference on the second occasion (est=-0.391). With this reference category a number of other potential interactions could be examined such as (a) those in the Control condition at baseline and (b) those in the Control condition on the follow-up occasion. Neither of these potential interactions 
were statistically significant. HEI scores were found to be significantly higher at 6 months than at baseline in the treatment group (est=-2.54, se $=0.39, P<0.001)$ (Table 3).

Taking NS-E as the reference category, NS-E was not significant for those in the control group but had a statistically significant effect on HEI scores in the Treatment group (est=1.71, se $=0.39, P<0.001)$. In other words, the effect of NS-E on HEI scores was different between conditions (ie. an interaction). This time $\mathrm{X}$ condition interaction, however, was not statistically significant (est $=-0.65$, se $=0.75, P=0.387)$.

Taking EHLoC as the reference category, EHLoC also had a statistically significant effect on HEI scores in the Treatment condition (est=1.06, se $=0.40, P=0.009$ ). Again, the interaction between time and condition was not significant (est=-0.55, se=0.80, $P=0.496$ ). There was no effect of IHLoC on HEI scores (est=-0.02, se=0.35, $P=0.671$ ), nor was the interaction between time and condition significant (est=0.94, se $=0.68, P=0.165$ ).

Taking S-RHI as the reference category, S-RHI had a statistically significant effect on HEI scores in the Treatment condition (est $=3.42$, se $=0.33, P<0.001$ ). The interaction between time and condition was statistically significant and indicated that S-RHI had an effect on HEI and that scores were significantly higher in the Treatment group at 6 months $(e s t=-1.44$, se=0.67, $P=0.032$ ). In other words, in the Treatment group (personalised nutrition), the coefficient for the regression of baseline S-RHI on HEI at 6 months (having controlled for baseline HEI) indicated a positive association with HEI and a statistically significant effect (0.05 level) on response to intervention. Habit strength at baseline also had a greater effect on HEI scores post-intervention in the Treatment (personalised nutrition) than the Control (nonpersonalised) group. 

between NS-E, Internal HLoC or External (EHLoC) at baseline and HEI scores postintervention.

Estimated Marginal Means (HEI)

\section{Mediterranean Diet (MDI)}

The Treatment group showed a time effect on MDI scores which increased between baseline and six months (est=-3.91, se $=0.07, P<0.001$ ). MDI scores were positively associated with EHLoC, S-RHI and NS-E in the Treatment group (Table 3). MDI scores were negatively associated with IHLoC and positively associated with S-RHI in the Control group. There was no significant association between MDI scores and IHLoC in the Treatment group or with EHLoC or NSE in the Control group. The level-1 variance was 1.36 se $=0.07$ and the level-2 random intercept value was $1.24 \mathrm{se}=0.10$.

\section{Time and Condition}

Using the Treatment condition from the second time point (6 months) as reference category an interaction between time and condition was employed. MDI scores were significantly higher at 6 months than at baseline in the Treatment group (est $=-0.39$, se $=0.07, P<0.001$ ) (Table 3). 
Taking NS-E as the reference category, NS-E was not significant for those in the Control

392

393

394 group but had a statistically significant effect on MDI scores (est $=0.25$, se $=0.70, P<0.001)$ in the Treatment group. In other words, the effect of NS-E on MDI scores was different for those in the different conditions i.e. an interaction. This interaction was not statistically significant (est=-0.11, se $=0.11, P=0.402)$.

Taking EHLoC as the reference category, EHLoC was positively associated with MDI scores in the treatment condition (est=0.31, se $=0.07, P<0.001$ ). Additional testing of the difference between the effects of EHLoC in both conditions, indicated this interaction was not significant (est=-0.12, se $=0.14, P=0.390)$.

IHLoC (reference category) had a significant effect on MDI scores in both Control and Treatment group. Testing of potential differential effects of IHLoC on MDI scores within the two conditions, indicated the interaction was not statistically significant (est $=0-.169$, se $=$ 0.121, $P=0.164$ ). IHLoC had no effect upon MDI scores (est=-0.04, se=0.06, $P=0.467$ ) nor was the interaction statistically significant (est=-0.17, se=0.12, $P=0.164)$.

Taking S-RHI as the reference category, S-RHI scores were statistically significantly related to MDI scores for both those in the Control and Treatment groups, with similar effects (est=0.42, se=0.06, $P<0.001$ ). When the effects of a potential interaction were tested, again, this was not found to be statistically significant (est=-0.03, se=0.12, $P=0.804$ ) (Table 3).

\section{Estimated Marginal Means (MDI)}

The EMM for the MDI score was 5.12 for those in the Control condition at 6 months $(\mathrm{SD}=$ 1.63). This was the same score that Controls had at baseline $(\mathrm{SD}=1.58)$. Those in the Treatment group had an EMM of $5.55(\mathrm{SD}=1.75)$ at 6 months, while at the baseline the value for this condition was $5.16(\mathrm{SD}=1.72)$. 


\section{DISCUSSION}

417 Primary analysis of the intervention results found that personalised advice was more effective than non-personalised advice in bringing about healthy dietary change (Celis-Morales et al., 2017). The objective of this analysis has been to evaluate whether Nutrition Self-Efficacy (NSE), Internal and External HLoC and habit strength (S-RHI) at baseline influenced responses to the intervention. The prediction was that those with higher scores on S-RHI, NS-E and IHLoC and lower scores on EHLoC would be more likely to respond to personalised nutrition advice by making healthy eating choices reflected in higher HEI and MDI scores.

As predicted, results indicated higher NS-E at baseline was associated with higher HEI and MDI scores which increased significantly in the treatment group post-intervention. This is consistent with previous qualitative research which emphasised the importance of motivational factors to personalised nutrition (Stewart-Knox et al., 2013; Rankin et al., 2016) and survey research indicating associations between self-efficacy and attitudes and intention to adopt personalised nutrition (Poínhos et al., 2014). This finding is also consistent with research linking self-efficacy to healthy eating (de Borba et al., 2021; Newby et al., 2020; Lo et al., 2019; Churchill et al., 2019; Naughton et al., 2015; Ferranti et al., 2014; Williams et al., 2012; Anderson et al., 2000). That NS-E did not differ between the control and intervention group post-intervention implies it did not impact upon response to the trial and is contrary to previous studies that have observed increased intake of vegetables (Bouwman et al., 2020), increased fruit and vegetable intake (Smith et al., 2020) and reduced fast food consumption (Smith et al., 2020) in response to enhanced self-efficacy. This could possibly be because average scores were lower than those measured in previous population studies (Naughton et al., 2015; Paxton and Sculthorpe, 1999). This bias was not explained by sample attrition as NS-E did not differ between completers and non-completers (Table 2). 

snacks (Wouters et al., 2018; Naughton et al., 2015) as well as intention to consume a range of foods (Rompotis et al., 2014; de Bruijn and van den Putte, 2009; de Bruijn et al., 2007; Brug et al., 2006; Honkanen and Olsen, 2005; Verbeke and Vackier, 2005), S-RHI scores were associated with higher HEI and MDI. S-RHI also affected response to the intervention and was associated with higher MDI and HEI scores in the Treatment than the Control group postintervention with moderate effect sizes. This is in keeping with previous interventions which found habit strength to be associated with frequent intake of fruit and vegetables (van Keulen et al., 2021; Bartle et al., 2019) and consumption of sugar-sweetened beverages (Judah et al., 2020). This is also consistent with survey research linking habit to frequent intake of high energy snacks (Wouters et al., 2018; Naughton et al., 2015) and intention to consume a range of foods (Rompotis et al., 2014; de Bruijn and van den Putte, 2009; de Bruijn et al., 2007; Brug et al., 2006; Honkanen and Olsen, 2005; Verbeke and Vackier, 2005). Although scores indicated that our sample were in the mid-range for habit strength (Gardner et al., 2011), they were on average lower than other samples (Naughton et al., 2015). That S-RHI was higher among those who completed the intervention (Table 2), highlights the importance of habit strength to compliance with healthy eating (Gardner et al., 2014) and should be fostered for interventions to be successful. Although S-RHI was associated with higher MDI scores over time, it was not associated with higher MDI scores in the Treatment compared with the Control group post-intervention. This suggests adherence to a Mediterranean diet may be driven more by external factors such as availability and the culture of food (Diaz Mendez et al., 2013; Fleischhacker et al., 2011) and less by individual factors such as habit.

Given previous research (Cheng et al., 2016; Stewart-Knox et al., 2013; Marteau et al., 2010) it was predicted that external (EHLoC) would be negatively associated with dietary indices. That higher EHLoC was associated with higher HEI and MDI scores and over time in 
the Treatment group, however, agrees with survey research (Jang and Baek, 2018) linking EHLoC to healthier eating. That average EHLoC was higher in our sample than reported in previous studies (Pudrovska, 2015; Paxton and Sculthorp, 1999) could imply a self-selection bias. Higher EHLoC has been associated with greater anxiety (Cheng et al., 2016). It is possible, therefore, that those with higher EHLoC are more anxious to improve their diet and are more likely to volunteer for an intervention despite their EHLoC orientation. This is consistent with analysis of responses from 3811 individuals who provided information about reasons for joining the study and among whom the most common reason (87\%) was "concerns for health" (Livingstone et al., 2016c). Previous studies have hinted at sex differences in how EHLoC is related to health behavior (Cobb-Clark et al., 2014; Stewart-Knox et al., 2009). That our sample was balanced by sex, randomised to condition and that no sex differences were observed in responses to any psychological variables at baseline, renders it unlikely that sex affected the result. It is also possible that the unidimensional measure of EHLoC employed

Previous research into personalised nutrition has suggested that high internal (IHLoC) could be an important driver of the uptake of and adherence to a personalised diet (Rankin et al., 2016; Poínhos et al., 2014; Cobb-Clark et al., 2014; Stewart-Knox et al., 2009). Contrary to prediction, however, IHLoC was unrelated to either of the dietary indices and did not differ between the control and treatment groups post-intervention. This is also contrary to previous survey research linking IHLoC to healthier eating (Jang and Baek, 2018; Rongen et al., 2014). Average scores on IHLoC were lower and with less variability than those observed in previous population studies (Pudrovska, 2015; Paxton and Sculthorp, 1999). A possible reason for our null results, therefore, could be that because volunteers were self-selected and as such, may have been driven by their low IHLoC which may have affected their responses. Individuals low on IHLoC may have volunteered to obtain extra support to achieve healthy eating. That 
there were no differences in IHLoC between those who completed and did not complete the intervention supports this theory. Previous studies have also produced null results (von Lengerke et al., 2007; Murphy et al., 2001; Schank and Lawrence, 1993). Where population groups have been studied relationships between IHLoC and health outcomes have tended to be weak (Cheng et al., 2016).

Collecting data on-line may have biased the sample toward those more comfortable with digital solutions. Analysis of the characteristics of those who volunteered $(\mathrm{N}=5500)$, however, indicated they were broadly similar to the European (EU) adult population (Livingstone et al., 2016c). Attrition affected the control group to a greater degree than the treatment group (Livingstone et al., 2016c) so that a greater proportion of the sample were in the treatment than the control group. Despite this discrepancy, there remained adequate numbers in both groups to enable meaningful analysis. A strength is that unlike previous dietary health interventions that have recruited from clinical populations (Olsen, 2016), the study employed a non-clinical apparently healthy sample. Another potential limitation inherent in this study is that country of residence was not included as a variable. A sensitivity analysis (see caption table 3 ) indicated that country had no effect on the interpretation of the fixed affects for either model (HEI or MDI) and suggesting that cross-country differences in Europe have no major influence. This was not surprising given the intervention was delivered on-line and personalised to individuals (not groups), Other studies have also found that once corrected for demographic variables, individuals across Europe share many characteristics (eg.Poínhos et al., 2014), hence, we would not have expected country to have influenced the results.' The lack of ethnic diversity in the final sample, however, limits the degree to which findings can be generalised to the wider EU population. Future research needs to consider more diverse representative samples (Olsen, 2016). 

results. FFQ's are subject to inaccuracy inherent in recall (MacDiarmid and Blundell, 1998). accurate than 'paper and pencil' versions and to produce better compliance (McGloin and Eslami, 2015). The online FFQ used was validated specifically for this project (Fallaize et al., 2014; Forster et al., 2014). The self-reported nature of the psychological measures may also have influenced the results (Fisher, 1993). The use of well-validated psychometric scales for assessment of psychological variables, however, will have gone some way toward reducing response bias.

Only scores on the psychological variables at baseline were included in the analysis so that no account was taken of potential changes following intervention. Given the aim was to determine the influence of pre-existing psychological traits on response to the intervention, we would not expect this to have unduly influenced outcomes. This study has focussed on traits that are enduring in the individual and which may have affected response to the RCT. Despite being collected more than six years previously, these data are appropriate to answer the research question and the time lapse will not have affected the relevance or practical implications of the results. Future research is required to determine any potential feedback loop between psychological factors and personalised nutrition advice.

\section{CONCLUSIONS}

534 Habit Strength appears particularly important to response to personalised nutrition. This analysis has implied that response to the Food4Me intervention was stronger in the Treatment group where HEI was the outcome. Prospective assessment of habit strength for each individua could prove useful in developing and communicating personalised dietary advice most effectively in practice. Personalised nutrition services should contain elements to target and 
enhance Habit strength taking into account individual barriers to healthy eating, food preferences, lifestyle and social circumstances. Advice may also need tailored so that those with lower habit strength receive additional help in integrating dietary advice into their daily routine and in sustaining healthy changes over time.

Although individual differences in nutrition self-effiacy, external health locus of control and habit strength did not impact upon dietary response to the intervention, they were associated with scores on dietary indices in both the control and intervention groups over the course of the intervention. This suggests that psychological traits will be important to consider in practice when providing nutritional advice (Rozga et al., 2020). Interventions aimed at changing these psychological traits may predict potential openness to future dietary change. Clients may be screened for traits associated with behaviour change during initial consultation so that service delivery, digital interface, goal setting, feedback and monitoring can be tailored to specific individual psychology. These findings also have implications for public health in that interventions should seek to enhance self-efficacy and habit strength in target groups.

To our knowledge, this appears to be the first study that has investigated the impact of psychological traits associated with dietary change on dietary response to personalised nutrition in a European sample of healthy volunteers We hope that these results will encourage others to consider including assessment of psychological constructs that influence dietary change when designing personalised nutrition offerings and in practice.

\section{REFERENCES}


560

561

562

563

564

565

566

567

568

569

570

571

572

573

574

575

576

577

578

579

580

581

582

583

AbuSabha, R. and Achterberg, C. (1997), "Review of self-efficacy and locus of control for nutrition and health-related behaviour", Journal of the American Dietetic Association, Vol. 97, pp.1122-1132.

Anderson, E.S., Winett, R.A. and Wojcik, J.R. (2000), "Social-cognitive determinants of nutrition behavior among supermarket food shoppers: A structural equation analysis", Health Psychology, Vol.19, pp.479-486.

Bandura, A. (1997), Self-Efficacy: The Exercise of Control. Worth Publishers.Bartle, T., Mullan, B., Allom, V. and Hasking, P. (2019), "The role of choice in eating behaviours", British Food Journal, Vol.121(11), pp.2696-2707.

de Borba, T.P., da Silva, M.V., Jomori, M.M., Bernardo, G.L., Fernandes, A.C., Proenca, R.P.D., Rockenbach, G. and Uggioni, P.L. (2021), "Self-efficacy in cooking and consuming fruits and vegetables among Brazilian University students: the relationship with sociodemographic characteristics”, British Food Journal, DOI:10.1108/BFJ-04-2020-0311.

Bouwman, E.P., Onwezen, M.C., Taufik, D., de Buisonje, D. and Ronteltap, A. (2020), "Brief self-efficacy interventions to increase healthy dietary behaviours: evidence from two randomised controlled trials", British Food Journal, Vol.122(11), pp.3297-3311.

Bracken, M.L. and Waite, B.M. (2020), Self-efficacy and nutrition related goal achievement of MyFitnessPal users ”, Health Education \& Behavior, Vol.47(5), pp.677-681.

Brug, J., de Vet, E., de Nooijer, J. and Verplanken, B. (2006), "Predicting fruit consumption: cognitions, intention and habits", Journal of Nutrition Education and Behavior, Vol.38, pp.7381.

de Bruijn, G.J. and van den Putte, B. (2009), “Adolescent soft drink consumption, television viewing and habit strength", Investigating clustering effects in the Theory of Planned Behaviour. Appetite, Vol.53, pp.66-75. 
de Bruijn, G.J., Kremers, S.P.J., de Vet, E., de Nooijer, J., van Mechelen, W. and Brug, J. (2007), "Does habit strength moderate the intention-behaviour relationship in the Theory of Planned behaviour? The case of fruit consumption", Psychology and Health, Vol.22, pp.899916.

de Bruijn, G.J. (2010), “Understanding college students' fruit consumption. Integrating habit strength in the theory of planned behaviour", Appetite, Vol.54, pp.16-22.

Callaghan, P. (1998), “Social support and locus of control as correlates of UK nurses' healthrelated behaviours", Journal of Advanced Nursing, Vol.28, pp.1127-1133.

Carey, R.N., Connell, L.E., Johnson, M., Rothman, A.J., de Bruijn, M., Kelly, M.P. and Michie, S. (2018), "Behavior change techniques and their mechanisms of action: a synthesis of links described in published intervention literature", Annals of Behavioral Medicine, Vol.53, pp.693707.

Celis-Morales, C., Lara, J. and Mathers, J.C. (2014), "Personalising nutritional guidance for more effective behaviour change", Proceedings of the Nutrition Society, Vol.74, pp.130-138.

Celis-Morales, C., Livingstone, K.M., Marsaux, C.F., Forster, H., O’Donovan, C.B., Woolhead, C., ... Mathers, J.C. (2015), "Design and baseline characteristics of the Food4Me study: a web-based randomised controlled trial of personalised nutrition in seven European countries", Genes and Nutrition, Vol.10, pp.1-13.

Celis-Morales, C., Livingstone, K.M., Marsaux, C.F., Macready, A.L., Fallaize, R., O’Donovan, C.B. et al. (2017), "Effect of personalized nutrition on health-related behaviour change: evidence from the Food4Me European randomized controlled trial.", International Journal of Epidemiology, Vol.46, 578-588. 
606 Cheng, C., Cheung, M.W.L. and Lo, B.C.Y. (2016), "Relationship of health locus of control 607 with specific health behaviours and global health appraisal: a meta-analysis and effects of

608

609

610

611

612

613

614

615

616

617

618

619

620

621

622

623

624

625

626

627

628

629

630 moderators", Health Psychology Reviews, Vol.10, pp.460-477.

Churchill, S., Pavey, L. and Sparks, P. (2019), “The impact of autonomy-framed and controlframed implementation intentions on snacking behaviour: the moderating effect of eating selfefficacy", Applied Psychology-Health and Wellbeing, Vol.11, pp.42-58.

Cobb-Clark, D.A., Kassenboehmer, S.C. and Schurer, S. (2014), "Healthy habits: the connection between diet, exercise and locus of control", Journal of Economics and Behavior in Organisations, Vol. 98, pp.1-28.

Davey, J., Herbst, J., Johns, R., Parkinson, J., Russell-Bennett, R. and Zainuddin, N. (2019), "The role of health locus of control in value co-creation for standard screening services", Journal of Service Theory and Practice, Vol.30(1), pp.S31-55.

Díaz Méndez, C., García Espejo, I., Gutiérrez Palacios, R. and Novo Vázquez, A. (2013), Spanish Eating Habits. Madrid: Ministerio de Agricultura, Alimentación y Medio Ambiente.

Fallaize, R., Forster, H., Macready, A.L., Walsh, M.C. Mathers, J.C. Brennan, L. et al. (2014), “Online Dietary Intake Estimation: Reproducibility and Validity of the Food4Me Food Frequency Questionnaire Against a 4-Day Weighed Food Record” Journal of Medical Internet Research, Vol.16(6), e190.

Ferranti, E.P., Narayan, K.M., Reilly, C.M., Foster, J., McCullough, M., Ziegler, T.R. et al. (2014), "Dietary self-efficacy predicts AHEI diet quality in women with previous gestational diabetes", Diabetes Education, Vol.40, pp.688-699.

Field, A. (2018), Discovering Statistics Using IBM SPSS Statistics. $5^{\text {th }}$ Edition. London: Sage Publications Ltd.

Fisher, R.J. (1993), “Social desirability bias and the validity of indirect questioning”, Journal of Consumer Research, Vol.20, pp.303-315. 
631 Fleischhacker, S.E., Evenson, K.R., Rodriguez, D.A. and Ammerman, A.S. (2011), “A systematic review of fast food access studies", Obesity Reviews, Vol.12(5), e460-e471.

633 Forster, H., Gallagher, C., O’Donovan, C.B., Woolhead, C., Walsh, M.C., Macready, A.L. et 634 al. (2014), "Online dietary intake estimation: the Food4Me food frequency questionnaire", 635 Journal of Medical Internet Research, Vol.16(6), e150.

Frosch, D., Mello, P. and Lerman, C. (2005), "Behavioral consequences of testing for obesity risk", Cancer Epidemiology and Biomarkers Preview, Vol.14, pp.1485-1489.

Galekop, M., Uyl-de Groot, C.A. and Redekop, M.M.J. (2021), “A systematic review of costeffectiveness studies of interventions with a personalised nutrition component in adults", Value in Health, Vol.24(3), pp.325-335.

Gardner, B., de Bruijn, G.J. and Lally, P. (2011), “A systematic review and meta-analysis of applications of the Self-Report Habit Index to nutrition and physical activity behaviours", Annals of Behavioral Medicine, Vol.42, pp.174-187.

Gardner, B., Sheals, K., Wardle, J. and McGowan, L. (2014), "Putting habit into practice, and practice into habit: a process evaluation and exploration of the acceptability of a habit-based dietary behaviour change intervention", International Journal of Behavioral Nutrition and Physical Activity, Vol.11, pp.135.

Gebhardt, W., van der Doef, M. and Paul, L. (2001), “The Revised Health Hardiness Inventory (RHHI-24): psychometric properties and relationship with self-reported health and health behavior in two Dutch samples", Health Education Research, Vol.16, pp.579-92. doi: 10.1093/her/16.5.579

Gomez, P., Boesen-Mariani, S. and Bruckert, E. (2018), "Psychological predictors of the combined adoption of physical exercise and dietary change among adults with hypercholesterolaemia”, Review of Epidemiology Sante Publique, Vol.66, pp.281-289. 
655 Greiner, B.H., Croff, J., Wheeler, D. and Miller, B. (2018), "Mediterranean diet adherence in

656

657

658

659

660

661

662

663

664

665

666

667

668

669

670

671

672

673

674

675

676

677

678

cardiac patients", American Journal of Health Behavior, Vol.42, pp.3-10.

Guenther, P.M., Kirkpatrick, S.I., Reedy, J., Krebs-Smith, S.M., Buckman, D.W., Dodd, K.W. et al. (2014), "The Healthy Eating Index-2010 is a valid and reliable measure of diet quality according to the 2010 Dietary Guidelines for Americans", Journal of Nutrition, Vol.144, pp.399-407.

Hoevaars, F.P.M., Berendsen, C.M.M., Pasman, W.J., van den Broek, B.E., de Hoogh, I.M. and Wopereis, S. (2020), "Evaluation of food-intake behavior in a healthy population personalised vs one-size-fits-all”, Nutrients, Vol.12(9), pp.2819.

Honkanen, P., Olsen, S.O. and Verplanken, B. (2005), "Intention to consume seafood - the importance of habit”, Appetite, Vol.45, pp.161-168.

Hwang, H. (2016), “The impact of social cognitive constructs on dietary behaviours in breast cancer survivors", Asian Oncology Nursing, Vol.16, pp.139-146.

Jang, K. and Baek, Y.M. (2018), "How to effectively design public health intervention: implications from the interaction effects between socioeconomic status and health locus of control beliefs on healthy dietary behaviours among US adults", Health \& Social Care in the Community, Vol.26(5), pp.664-674.

Joost, H., Gibney, M.J., Cashman, K.D., Gorman, U., Hesketh, J.E., Mueller, M., .. Mathers, J.C. (2007), "Personalised nutrition: status and perspectives", British Journal of Nutrition, Vol.98, pp.26-31.

Judah, G., Mullane, B., Yee, M., Johansson, L., Allom, V. and Liddelow, C. (2020), “A habitbased randomised controlled trial to reduce sugar sweetened beverage consumption: the impact of the substituted beverage on behaviour and habits strength", International Journal of Behavioural Medicine, Vol.27(6), pp.623-635. 
679 van Keulin, H.M., van Breukelen, G., de Vries, H., Brug, J. and Mesters, I. (2020), “A randomised controlled trial comparing community lifestyle interventions to improve adherence to diet and physical activity recommendations the vitalUM study" European Journal of 682 Epidemiology, Vol.36(3), pp.345 to 360.

Kushida, O., Iriyama, Y., Murayama, N., Saito, T. and Yoshita, K. (2017), “Associations of self-efficacy, social support and knowledge with fruit and vegetable consumption in Japanese workers", Asia Pacific Journal of Clinical Nutrition, Vol.26, pp.725-730.

Lee, H.C., Chang, C.T., Cheng, Z.H. and Chen, Y-T. (2019), "Will an organic label always 687 increase food consumption? It depends on food type and consumer preferences in health locus of control”, Food Quality and Preference, Vol.63, pp.88-96. von Lengerke, T., Janssen, C. and John, J. (2007), “Sense of coherence, health locus of control and quality of life in obese adults: physical limitations and psychological normalcies", International Journal of Public Health, Vol.52, pp.16-26.

692 Livingstone, K.M., Celis-Morales, C., Lara, J., Woolhead, C., O’Donovan, C.B., Forster, H. et al. (2016a), "Clustering of adherence to personalised dietary recommendations and changes in healthy eating index within the Food4Me study", Public Health Nutrition, Vol.19, pp.32963305.

Livingstone, K.M., Celis-Morales, C., Navas-Carretero, S., San-Cristobal, R., Macready, A.L., 697 Fallaize, R. et al. (2016b), "Effect of an internet-based, personalised nutrition randomized trial on dietary changes associated with the Mediterranean diet: the Food4Me study", American Journal of Clinical Nutrition, Vol.104, pp.288-97.

700 Livingstone, K.M., Celis-Morales, C., Navas-Carretero, S., San-Cristobal, R., O’Donovan, C.B., Forster, H. et al. (2016c), "Profile of European adults interested in internet-based personalised nutrition", European Journal of Nutrition, Vol.55, pp.759-769. 

efficacy and cooking confidence are associated with fruit and vegetable intake in a cross-

705

706

707

708

709

710

711

712

713

714

715

716

717

718

719

720

721

722

723

724

725

726 sectional study in rural women”, Eating Behaviors, Vol.33, pp.34-39.

MacDiarmid, J. and Blundell, J. (1998), “Assessing dietary intake: who, what and why of under-reporting”, Nutrition Research Reviews, Vol.11, pp.231-253.

Madden, J., Williams, C.M., Calder, P.C., Leitz, G., Miles, E.A., Cordell, H., ... Minihane, A.M. (2011), “The impact of common gene variants on the response of biomarkers of cardiovascular disease (CVD) risk to increased fish oil fatty acids intakes" Annual Review of Nutrition, Vol.31, pp.203-34.

Marshall, S.J., Livingstone, K.M., Celis-Morales, C., Forster, H., Fallaize, R., O’Donovan, C.B. et al. (2016), "Reproducibility of the online Food4Me food-frequency questionnaire for estimating dietary intakes across Europe”, Journal of Nutrition, Vol.146, pp.1068-1075.

Marteau, T.M., French, D.P., Griffin, S.J., Prevost, A., Sutton, S., Watkinson, C., ... Hollands, G.J. (2010), "Effects of communicating DNA-based disease risk estimates on risk-reducing behaviours”, Cochrane Database Systematic Review, Vol.6(10), CD007275.

Marteau, T., Senior, V., Humphries, S.E., Bobrow, M., Cranston, T., Crook, M.A., ... Iverson, A. (2014), "Psychological impact of genetic testing for familial hypercholesterolemia within a previously aware population: a randomized controlled trial", American Journal of Medical Genetics, Vol.128, pp.285-293.

Martinez-Gonzalez, M.A., Corella, D., Salas-Salvado, J., Ros, E., Covas, M.I., Fiol, M., Warnberg, J., Aros, F., Ruiz-Gutierrez, V., Lamuela-Raventos, R.M., Lapetra, J., Munoz, M.A., Martinez, J.A., Saez, G., Serra-Majem, L., Pinto, X., Mitjavila, M.T., Tur, J.A., Portillo, M.D. and Estruch, R. (2012), "Cohort profile: design and methods of the PREDIMED study", International Journal of Epidemiology, Vol.41(2), pp.377-385. 
McGloin, A.F. and Eslami, S. (2015), "Digital and social media opportunities for dietary behaviour change", Proceedings of the Nutrition Society, Vol.74, pp.139-148.

Murphy, P.A., Prewitt, T.E., Bote, E., West, B. and Iber, F.L. (2001), “Internal locus of control and social support associated with some dietary changes in elderly participants in a diet intervention trial". Journal of the American Dietetic Association, Vol.101, pp.203-208.

Naughton, P., McCarthy, M. and McCarthy, S. (2015), “Acting to self-regulate unhealthy eating habits. An investigation into the effects of habit, hedonic hunger and self-regulation on sugar consumption from confectionary foods", Food Quality and Preference, Vol.46, pp.173183.

Newby, K., Teah, G., Cooke, R., Li, X.R., Brown, K., Salisbury-Finch, B., ... Williams, S.L. (2020), "Do automated digital health behaviour change interventions have a positive effect on self-efficacy? A systematic review and meta-analysis", Health Psychology Reviews, DOI:10.1080/17437199.2019.1705873

Olsen, C.M. (2016), "Behavioural nutrition interventions using e-and-m-health communication Technologies", Annual Review of Nutrition, Vol.36, pp.647-64.

Ordovas, J.M., Ferguson, L.R., Tai, E.S. and Mathers, J.C. (2018), "Personalised nutrition and health”, British Medical Journal, Vol.361: bmj.k2173. doi: 10.1136/bmj.k2173.

Otto, C., Bischof, G., Rumpf, H.J., Meyer, C., Hapke, U. and Ulrich, J. (2011), "Multiple dimensions health locus of control in a representative population sample: ordinal factor analysis and cross-validation of an existing three and a new four factor model", BMC Medical Research Methodology, Vol.11, pp.114. doi: 10.1186/1471-2288-11-114.

Paxton, S.J. and Sculthorpe, A. (1999), "Weight and health locus of control beliefs in an Australian community sample", Psychology and Health, Vol.14, pp.417-431. 
750

751

752

753

754

755

756

757

758

759

760

761

762

763

764

765

766

767

768

769

770

771

772

773

Phelan, S., Halfman, T., Pinto, A.M. and Foster, G.D. (2020), "Behavioral and psychological strategies of long-term weight loss maintainers in a widely available weight management program", Obesity, Vol.28, pp.421-428.

Poínhos, R., van der Lans, I.A., Rankin, A., Fischer, A.R., Bunting, B.P., ... Frewer, L.J. (2014), "Psychological determinants of consumer acceptance of personalised nutrition in 9 European countries", PloS One 9, e110614.

Pudrovska, T. (2015), “Gender and health control beliefs among middle-aged and older adults", Journal of Aging and Health, Vol.27, pp.284-303.

Rankin, A., Kuznesof, S., Frewer, L., Orr, K., Davison, J., de Almeida, M.D.V., and StewartKnox, B. (2016), "Public perceptions of personalised nutrition through the lens of Social Cognitive Theory”. Journal of Health Psychology, Vol.22, pp.1233-1242.

Rees, J.H., Bamberg, S., Jager, A., Victor, L., Bergmeyer, S. and Friese, M. (2018), "Breaking the habit: on the highly habitualized nature of meat consumption and implementation intentions as one effective way of reducing it", Basic and Applied Social Psychology, Vol.40, pp.136147.

Rollo, M.E., Haslam, R.L. and Collins, C.E. (2020), "Impact on dietary intake of two levels of technology-assisted personalised nutrition: a randomised controlled trial", Nutrients, Vol.12(11), pp.3334.

Rompotis, C.J., Grove J.R. and Byrne, S.M. (2014), "Benefits of habit-based informational interventions: a randomized controlled trial of fruit and vegetable consumption". Australian and New Zealand Journal of Public Health, Vol.38, pp.247-252.

Rongen, A., Robroek, S.J.W. and Burdoff, A. (2014), “The importance of internal health beliefs for employees' participation in health promotion programs", Preventative Medicine, Vol.67, pp.330-334. 
Rotter, J.B. (1966), “Generalized expectancies for internal versus external control of

775

776

777

778

779

780

781

782

783

784

785

786

787

788

789

790

791

792

793

794

795

796 reinforcement”, Psychology Monographs, Vol.80, pp.1-28.

Ryon, H.S. and Gleeson, M.E.J. (2014), “The role of LoC in daily life”. Personality and Social Psychology, Vol.40, pp.121-131.

San-Cristobal, R., Navas-Carretero, S., Celis-Morales, C., Livingstone, K.M., Stewart-Knox, B., Rankin, A. et al. (2017), "Capturing health and eating status through a nutritional perception screening questionnaire (NPSQ9) in a randomised internet-based personalised nutrition intervention: the Food4Me study". International Journal of Behavioral Nutrition and Physical Activity, Vol.14, pp.168.

Schank, M.J. and Lawrence, D.M. (1993), "Young-adult women - lifestyle and health locus of control”, Journal of Advanced Nursing, Vol.18, pp.1235-1241.

Schwarzer, R. and Renner, B. (2000), "Social-cognitive predictors of health behavior: Action self-efficacy and coping self-efficacy”, Health Psychology, Vol.19, pp.487-95.

Smith, M.L., Lee, S., Towne, S.D., Han, G., Quinn, C., Pena-Purcell, N.C. and Ory, M.G. (2020), "Impact of a behavioural intervention on diet, eating patterns, self-efficacy and social support", Journal of Nutrition Education and Behavior, Vol.52(2), pp.180-186.

Stewart-Knox, B., Bunting, B.P., Gilpin, S., Parr, H.J., Pinhao, S., de Almeida, M.D.V. and Gibney, M. (2009), "Attitudes toward genetic testing and personalised nutrition in a representative sample of European consumers", British Journal of Nutrition, Vol.101, pp.982989.

Stewart-Knox, B., Kuznesof, S., Robinson, J., Rankin, A., Orr, K., Duffy, M. ... Frewer, L. (2013), "Factors influencing European consumer uptake of personalised nutrition. Results of a qualitative analysis", Appetite, Vol.66, pp.67-74. 
Swan, E., Bouwman, L., Hiddick, G.J., Aarts, N. and Koelen, M. (2015), "Profiling healthy eaters", Determining factors that predict healthy eating practices among Dutch adults. Appetite, Vol.89, pp.122-130.

Verbeke, W. and Vackier, L. (2005), "Individual determinants of fish consumption. Application of the theory of planned behaviour", Appetite, Vol.44, pp.67-82.

Verhoeven, A., Adriaanse, M., Evers, C. and Ridder, D. (2012), "The power of habits: unhealthy snacking behaviour is primarily predicted by habit strength", British Journal of Health Psychology, Vol.17, pp.758-770.

Verplanken, B. and Orbell, S. (2003), "Reflections on Past Behavior: A Self-Report Index of Habit Strength”, Journal of Applied Social Psychology, Vol.33, pp.1313-1330.

Wallston, K.A., Wallston, B.S. and Devellis, R. (1978), "Development of multidimensional health locus of control scales (MHLC)" Health Education Monographs, Vol.6, pp.160-170.

Welsh, J.D. and Ellis, E.M. (2018), "Sex differences in the Association of perceived ambiguity, cancer fatalism and health related self-efficacy with fruit and vegetable consumption", Journal of Health Communication, Vol.23(12), pp.984-992.

Williams, L.K., Thornton, L. and Crawford, D. (2012), “Optimising women's diets. An examination of factors that promote healthy eating and reduce the likelihood of unhealthy eating", Appetite, Vol.59, pp.41-46.

Witte, K. and Allen, M. (2000), “A meta-analysis of fear appeals: implications for effective public health campaigns", Health Education and Behavior, Vol.27, pp.591-615.

Wouters, S., Thewissen, V., Duif, M., van Bree, R.J.H., Lechner, L. and Jacobs, N. (2018), "Habit strength and between-meal snacking in daily life: the moderating role of level of education", Public Health Nutrition, Vol.21(14), pp.2595-2605. 
821 Table 1. Mean $(m)$ and standard deviation $(s d)$ for Healthy Eating Index (HEI), Mediterranean

822 Diet Index (MDI), Self-Report Habit Index (S-RHI), Nutrition Self-Efficacy (NS-E), Internal

823 and External Health Locus of Control (HLoC) scores for individuals randomized to Control

824 (non-personalised advice) and Treatment (personalized nutrition advice) groups at baseline and

825 at 6 months post-intervention.

Baseline

\section{Post-Intervention}

\begin{tabular}{|c|c|c|c|c|c|c|c|c|}
\hline & \multicolumn{2}{|c|}{ Control $(n=360)$} & \multicolumn{2}{|c|}{ Treatment $(n=1120)$} & \multicolumn{2}{|c|}{ Control $(n=312)$} & \multicolumn{2}{|c|}{ Treatment $(n=958)$} \\
\hline & $m$ & $s d$ & $m$ & $s d$ & $m$ & $s d$ & $m$ & $s d$ \\
\hline HEI & 49.59 & 9.51 & 49.07 & 10.02 & 51.99 & 9.27 & 52.99 & 9.55 \\
\hline MDI & 5.17 & 1.58 & 5.10 & 1.72 & 5.32 & 1.63 & 5.58 & 1.75 \\
\hline IHLoC & 3.84 & 0.70 & 3.89 & 0.67 & 3.78 & 0.63 & 3.86 & 0.67 \\
\hline EHLoC & 4.37 & 0.57 & 4.42 & 0.56 & 4.41 & 0.60 & 4.52 & 0.55 \\
\hline S-RHI & 3.30 & 0.74 & 3.30 & 0.78 & 3.43 & 0.68 & 3.45 & 0.73 \\
\hline NS-E & 3.20 & 0.54 & 3.24 & 0.54 & 3.61 & 0.71 & 3.66 & 0.73 \\
\hline
\end{tabular}

826

827

828

829

830

831

832

833

834

835

836

837 

intervention.

840

841

\begin{tabular}{cccccc} 
& \multicolumn{2}{c}{$\begin{array}{c}\text { Completers } \\
(\mathrm{n}=1256)\end{array}$} & \multicolumn{2}{c}{$\begin{array}{c}\text { Non- } \\
\text { Completers } \\
(\mathrm{n}=309)\end{array}$} & \multirow{2}{*}{$P$ value } \\
& Mean & $\mathrm{sd}$ & Mean & $\mathrm{sd}$ & \\
\cline { 1 - 5 } & 3.23 & 0.54 & 3.24 & 0.55 & 0.833 \\
\hline N-SE & 4.14 & 0.47 & 4.16 & 0.49 & 0.951 \\
\hline HLoC & 3.88 & 0.68 & 3.89 & 0.68 & 0.542 \\
\hline IHLoC & 4.41 & 0.56 & 4.43 & 0.57 & 0.721 \\
\hline EHLoC & 3.33 & 0.76 & 3.18 & 0.82 & $0.004^{*}$
\end{tabular}

842

843

844

845

846

847

848

849

850

851

852

853

854 
Table 3. Estimates of Fixed Effects for Internal (IHLoC) and External Health Locus of Control 856 (EHLoC), Self-Report Habit Index (S-RHI) and Nutrition Self-Efficacy (NS-E), Healthy Eating Index 857 (HEI) and Mediterranean Diet Index (MDI) outcomes. Interactions for the control and treatment groups 858 at baseline and post-intervention ${ }^{1}$.

\begin{tabular}{lcccccc}
\hline & \multicolumn{3}{c}{ Healthy Eating Index } \\
& \multicolumn{1}{c}{ (HEI) } & \multicolumn{3}{c}{ Mediterranean Diet Index } \\
& Est. (s.e.) & $\mathbf{t}$ & $\mathbf{p}$ & Est. $($ s.e. $)$ & $\mathbf{t}$ & $\mathbf{p}$ \\
\hline Intercept & $30.66(2.29)$ & 13.42 & $<.001$ & $2.08(.40)$ & 5.15 & $<.001$ \\
Baseline * Control & $3.56(4.41)$ & .81 & .420 & $1.32(.78)$ & 1.69 & .091 \\
Post-Intervention * Control & $5.02(4.51)$ & 1.11 & .265 & $1.24(.80)$ & 1.56 & .120 \\
Baseline * Treatment & $-2.54(.39)$ & -6.49 & $<.001$ & $-3.9(.71)$ & -5.53 & $<.001$ \\
IHLoC * Control & $.80(.58)$ & 1.36 & .172 & $-.21(.10)$ & -2.07 & .039 \\
IHLoC * Treatment & $-.15(.35)$ & -.42 & .671 & $-.05(.06)$ & -.73 & .467 \\
EHLoC * Control & $.51(.70)$ & .74 & .461 & $.19(.12)$ & 1.55 & .122 \\
EHLoC * Treatment & $1.06(.40)$ & 2.63 & $\mathbf{. 0 0 9}$ & $.31(.07)$ & 4.38 & $<.001$ \\
S-RHI *Control & $1.98(.58)$ & 3.40 & .001 & $.39(.10)$ & 3.76 & $<.001$ \\
S-RHI * Treatment & $3.42(.33)$ & 10.37 & $<.001$ & $.42(.06)$ & 7.16 & $<.001$ \\
NS-E * Control & $1.06(.64)$ & 1.66 & .098 & $.14(.11)$ & 1.21 & .225 \\
NS-E * Treatment & $1.71(.39)$ & 4.33 & $<.001$ & $.25(.07)$ & 3.57 & $<.001$ \\
\hline
\end{tabular}

$860{ }^{1}$ Country of residence was used as a covariate to check if the inclusion of these additional seven

861 variables would have any significant effect on interpretation of the results. Sensitivity analysis

862 indicated that the country covariates made no difference to the statistical significance ( 0.05 level) of

863 the results. The results, therefore, are reported without the inclusion of country. 